\title{
Synthesis of carbon dots-assisted MgAl-LDH hollow microspheres with hierarchical structure for the effective removal of Congo red from wastewater
}

\author{
Zhigang Jia*, Cong Han, Rui Chang, and Daqing Zhang \\ School of Chemistry and Chemical Engineering, Anhui University of Technology, Ma'anshan 243002, Anhui Province, P R China
}

\begin{abstract}
Hierarchical hollow Mg-Al layered double hydroxide microspheres (HHMs) are successfully prepared by hydrothermal treatment in the presence of carbon dots (CDs). Morphology and structure of the as-prepared samples are characterized using XRD, SEM, FT-IR, and TEM techniques. The growth process of HHMs has been investigated in detail, and Ostwald ripening mechanism is suggested for the hierarchical growth of HHMs. Adsorption isotherms and adsorption kinetics of HHMs for congo red (CR) are investigated. Langmuir and Temkin model are more fitted to the experimental data of CR isotherm adsorption. Adsorption kinetic data obeys the pseudo-second-order kinetic model. Moreover, thermodynamic parameters $\left(\Delta \mathrm{G}^{\mathrm{o}}, \Delta \mathrm{H}^{\circ}\right.$ and $\left.\Delta \mathrm{S}^{\circ}\right)$ show that the $\mathrm{CR}$ adsorption onto HHMs is an endothermic and spontaneous process. The as-prepared HHMs could be a potential adsorbent for wastewater treatment containing anion dyes.
\end{abstract}

\section{Introduction}

Dyes with high stability have been widely used in many industries. Over 700,000 tons of various dyes are consumed in textile dyeing, food processing, papermaking, cosmetics and pharmaceutical process [1]. More than $20 \%$ of effluent pollution related with dyes is produced each year. Excess dyes are released into water body and results in the quantity of dyeing wastewater in industrial production. However, many dyes have detrimental influence on environmental safety and human health due to toxicity and teratogenic effect. Therefore, it becomes an important issue for modern industrial society to remove dyes form wastewater. During the past decades, various methods have been explored for the treatment of dye-containing wastewater, and adsorption treatment is proved to be the most prospective method due to its efficient and economic process. The adsorbent with excellent performance is the key of adsorption technology. Exploration of novel adsorbent with high adsorption capacity and low cost is still a challenge for the practical application of adsorption method.

Layered double hydroxides (LDHs) with simple structure and flexible composition are a family of inorganic layered compounds containing positively charged metal layers and intercalated anions. The intercalated anions can easily be replaced by other anions in LDHs by anion exchange. LDHs have high removal tendency for anionic dyes. However, there exit considerable difficulties in separating and reclaiming LDHs adsorbent in liquid systems due to colloidal dispersion of $2 \mathrm{~d}$ (two-dimensional) nanosheets.

To solve the above issues, assembly of $2 \mathrm{~d}$ nanosheet into $3 \mathrm{~d}$ micro-scale superstructures is an effective method. For example, hierarchically porous NiAl-LDH microspheres obtained via sodium citrateassisted solvothermal route displays high adsorption performance for p-nitrophenol [2]. Hierarchical ZnAl$\mathrm{Cl}$ type LDH has highly efficient adsorption rates and adsorption capacities for the removal of conge red and methyl orange [3]. Flower-like $\mathrm{Mg} 2 \mathrm{Al}-\mathrm{Cl} \mathrm{LDH}$ microspheres show high sorption capacity for methyl orange [4].

Carbon dots (CDs) have attracted extensive attention due to the potential application in biological labeling, sensing, nanobiotechnology, biomedicine, photocatalysis, and so on. Due to rich surface functional groups on the surface, including amine, carboxyl, carbonyl, and hydroxyl groups, CDs can form complexes with metal cations or interact with the special plane of crystal during the crystal growth period. However, functional groups of CDs greatly are closely related with their source. The variation of functional groups $(-\mathrm{OH},-\mathrm{COOH}, \mathrm{C}-\mathrm{O})$ of $\mathrm{CDs}$ may result in obvious change for crystal growth.

In this work, hollow LDH microspheres (HHMs) with hierarchical structure have been synthesized with the assistance of carbon dots derived from citric acid. The $2 \mathrm{~d}$ nanosheets are self-assembled into threedimensional MgAl-LDH hollow micro/nano-structures with high anion-exchange capacity. The formation mechanism of HHMs is investigated in detail. Congo red $(\mathrm{CR})$ is widely used in many fields, such as textiles,

\footnotetext{
${ }^{*}$ Corresponding author: zjchemyue@126.com
} 
paper, rubber and plastic industries. As a kind of typical dye, CR is employed as model pollutant. The as-synthesized hollow hierarchical MgAl-LDH exhibits high adsorption performance for the removal of Congo red (CR) dye. Kinetic, isotherm and thermodynamics of adsorption are investigated in detail.

\section{Experimental}

\subsection{Materials}

$\mathrm{Mg}\left(\mathrm{NO}_{3}\right)_{2} \cdot 6 \mathrm{H}_{2} \mathrm{O}, \quad \mathrm{Al}\left(\mathrm{NO}_{3}\right)_{3} \cdot 9 \mathrm{H}_{2} \mathrm{O}$ and urea were purchased from Sinopharm Chemical Reagent Co., Ltd (Shanghai, China). Citric acid (99.7\%) and congo red $\left(\mathrm{C}_{32} \mathrm{H}_{22} \mathrm{~N}_{6} \mathrm{Na}_{2} \mathrm{O}_{6} \mathrm{~S}_{2}\right)$ was purchased from Tianjin chemical Co., Ltd (China). The water used for LDH synthesis and treatment processes is distilled water.

\subsection{Synthesis of Carbon dots (CDs) solution}

CDs were synthesized in a one-step pyrolysis process from citric acid according to the reported method [5]. Typically, $8 \mathrm{~g}$ citric acid was added to the beaker and heated at $180^{\circ} \mathrm{C}$ until yellowish-brown gel was formed. Then, the gel was cooled to room temperature and dissolved in $200 \mathrm{~mL}$ of $0.5 \mathrm{M} \mathrm{NaOH}$ solution. The $\mathrm{pH}$ of solution is set to 7 .

\subsection{Synthesis of the HHMs}

HHMs were prepared by urea hydrolysis method. The $\mathrm{Mg} / \mathrm{Al}$ molar ratio of all the samples was kept constant at 2.0. Typically, $\mathrm{Mg}\left(\mathrm{NO}_{3}\right)_{2} \cdot 6 \mathrm{H}_{2} \mathrm{O} \quad(6 \mathrm{mmol})$ and $\mathrm{Al}\left(\mathrm{NO}_{3}\right)_{3} \cdot 9 \mathrm{H}_{2} \mathrm{O}(3 \mathrm{mmol})$, urea $(30 \mathrm{mmol})$ and $12 \mathrm{~mL}$ CDs solution were added into $60 \mathrm{~mL}$ distilled water and sonicated for $10 \mathrm{~min}$. Next, the resulting solution was transferred into the $100 \mathrm{~mL}$ Teflon-lined autoclave at $150^{\circ} \mathrm{C}$ for $10 \mathrm{~h}$. Finally, the products were washed with deionized water and dried at $80^{\circ} \mathrm{C}$ in an air to obtain HHMs, and the mass of HHMs was weighed to acquire the output and efficiency of the product.

\subsection{Characterizations}

Morphology of the as-obtained samples was observed by scanning electron microscopy (SEM, JSM-6490LV) and transmission electron microscopy (TEM, JEOL JEM-1400). X-ray powder diffraction patterns were obtained by Bruker D8-Advance with $\mathrm{Cu} K \alpha$ radiation $(\lambda=1.5418 \mathrm{~A})$. FTIR measurements were collected in the range of $4000-500 \mathrm{~cm}^{-1}$ by Nicolet 5700 spectrometer (Thermo Nicolet Corporation, US).

\subsection{Adsorption experiment}

Adsorption experiments were performed out using conge red (CR) solution with predetermined adsorbent. The solutions were placed in an incubator shaker (New Brunswick Scientific) for $2 \mathrm{~h}$ at $25^{\circ} \mathrm{C}$. All the concentrations were measured at the wavelength corresponding to maximum absorbance, $\lambda_{\max }=497 \mathrm{~nm}$, using UV-Vis spectrophotometer (INESA 721G). Adsorption kinetic studies were performed by adding $10 \mathrm{mg}$ of the adsorbent into $30 \mathrm{~mL}$ of CR solution $(20$ $\mathrm{mg} \mathrm{L}^{-1}$ ) at $25^{\circ} \mathrm{C}$ and the concentration of solution was detected at pre-set time intervals. Adsorption isotherm tests were carried out by $10 \mathrm{mg}$ adsorbent to $30 \mathrm{~mL}$ of CR solution (20 mg L L $\left.-160 \mathrm{mg} \mathrm{L}^{-1}\right)$ at different temperatures $(303-323 \mathrm{~K})$ for $2 \mathrm{~h}$. In order to reduce the test error, statistical determination of experiment was carried-out for each run. Adsorption capacities of $\mathrm{CR}$ at any time $\mathrm{q}_{\mathrm{t}}\left(\mathrm{mg} \mathrm{g}^{-1}\right)$ and at equilibrium $\mathrm{q}_{\mathrm{e}}(\mathrm{mg}$ $\left.\mathrm{g}^{-1}\right)$ were calculated as follows:

$$
\begin{aligned}
& q_{t}=\frac{\left(c_{0}-c_{t}\right) V}{m} \\
& q_{e}=\frac{\left(c_{0}-c_{e}\right) V}{m}
\end{aligned}
$$

where $\mathrm{C}_{0}, \mathrm{C}_{\mathrm{t}}$ and $\mathrm{C}_{\mathrm{e}}\left(\mathrm{mg} \mathrm{\textrm {L } ^ { - 1 }}\right)$ were the liquid phase concentrations of Congo red at initial period, adsorption at any time and adsorption equilibrium, respectively. Where $\mathrm{V}$ was the volume of solution (L) and $\mathrm{m}$ was the mass of adsorbent used $(\mathrm{g})$.

\section{Results and discussion}

\subsection{The formation mechanism CDs-assisted HHMs}

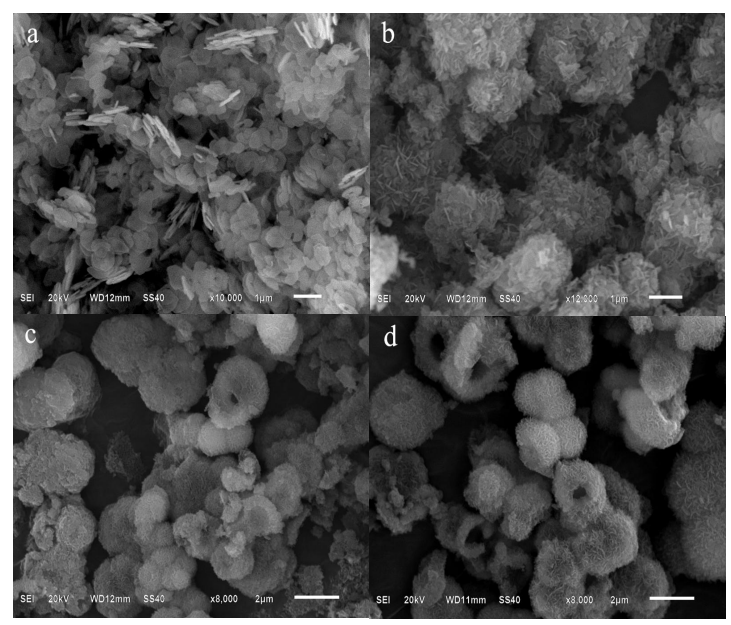

Figure 1. SEM images of Mg-Al LDH samples controlled by different volume of CDs solution (a: $0 \mathrm{~mL}$; a: $3 \mathrm{~mL}$; a: $6 \mathrm{~mL}$; a: $9 \mathrm{~mL}$ )

Figure 1 shows the SEM overview of Mg-Al-LDH morphology formed using various volume of CDs solution. As shown in Figure 1a, plenty of nanosheets with typical $2 \mathrm{~d}$ structure are obtained when no CDs are added in reaction system. With the increasing volume of CDs solution $(3 \mathrm{~mL}), 2 \mathrm{~d}$ nanosheets begin to randomly aggregate into micro-scaled cluster with irregular shape (Figure 1b). When the volume of CDs solution reaches $6 \mathrm{~mL}$, the as-obtained products are sphere-like morphology and incomplete half-sphere structure, and the microsphere is about 2 micrometer in diameter as shown in Figure 1c. The nanosheet-like structure can be clearly seen, indicating the micorspheres are constructed by nanosheets as basic 
unit. Remarkably, the microspheres are hollow structure with a little hole in the center of sphere and the diameter of the hole is about $100 \mathrm{~nm}$. Once the volume of CDs solution is enhanced to $9 \mathrm{~mL}$, relatively complete sphere constructed by $2 \mathrm{~d}$ nanosheets is formed with obvious hollow structure (Figure 1d). The yield of the final HHMs is $83.2 \%$. Meng et al prepared $3 \mathrm{D}$ porous $\mathrm{Mg}-\mathrm{Al}-\mathrm{LDH}$ microspheres with $\mathrm{CDs}$ as structure-directing agent. However, hollow Mg-AlLDH microspheres are obtained in our study. We believe that the difference in morphology may ascribe to the source of CDs.

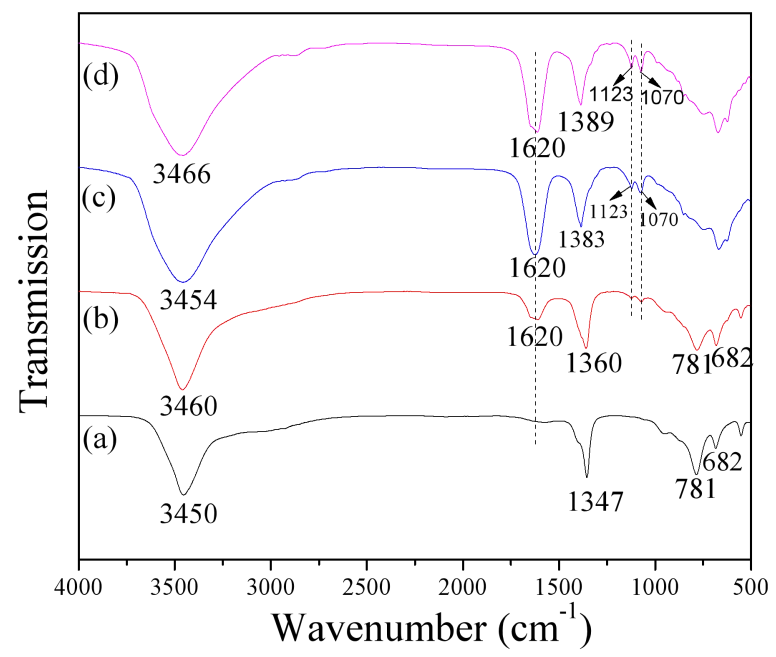

Figure 2. FTIR spectra of Mg-Al LDH samples controlled by different volume of CDs solution (a: $0 \mathrm{~mL}$; b: $3 \mathrm{~mL}$; c: $6 \mathrm{~mL}$; d: $9 \mathrm{~mL}$ )

FTIR spectra of the as-prepared LDHs with different volume of CDs are depicted in Figure 2. As shown in Figure 2a, the stretching of $-\mathrm{OH}$ groups associated with the interlayer water molecular locate at the broad band at about $3450 \mathrm{~cm}^{-1}$. The antisymmetric stretching vibration ( $V_{3}$ mode) of carbonate $\left(v_{\mathrm{CO}}\right)$ is referred to the band at $1347-1389 \mathrm{~cm}^{-1}$. Weak bands in the range of $500-800 \mathrm{~cm}^{-1}$ can be assigned to metaloxygen lattice vibrations [6]. As shown in Figure 2b-c, the as-prepared LDHs reveals the stronger absorption peaks at $1620 \mathrm{~cm}^{-1}$ than that of the raw LDHs, suggesting $\mathrm{C}=\mathrm{O}$ and $\mathrm{C}-\mathrm{O}-\mathrm{C}$ groups (oxygen-rich functional groups) attributed to $\mathrm{CDs}$ are introduced in the LDHs. Furthermore, the relative intensity of adsorption peak at $1620 \mathrm{~cm}^{-1}$ gradually becomes stronger, indicating the increasing amount of CDs in the as-obtained LDH samples.

Effect of reaction temperature on the morphology is also investigated. SEM images of the samples obtained at the reaction temperature of $90^{\circ} \mathrm{C}, 120^{\circ} \mathrm{C}$ and $150^{\circ} \mathrm{C}$ are shown in Figure 3. At the hydrothermal temperature of 90 and $120^{\circ} \mathrm{C}$, the products are all particles with smooth surface as shown in Figure $3 \mathrm{a}$ and $3 \mathrm{~b}$, respectively. The particles prepared at $120^{\circ} \mathrm{C}$ have even more uniform size. No obvious sheet-like structure can be observed in these samples. When the hydrothermal temperature reaches $150^{\circ} \mathrm{C}$, hollow microspheres with nanosheets on the surface can be clearly seen, indicating the crystallization increase with the increasing reaction temperature (Figure 3c). These results indicate that hydrothermal temperature has important influence for HHMs. Low temperature is not enough to grow petals, and only microcrystal spheres are formed. With the increasing hydrothermal temperature, the petals of the hierarchical structures begin to come into being, grow and finally develop into nanoplates. The well-defined plates are the fundamental unit for the formation of hierarchical structures. As a result, the hollow Mg-Al-LDH microspheres with a good dispersion are obtained when the hydrothermal temperature reaches $150^{\circ} \mathrm{C}$.

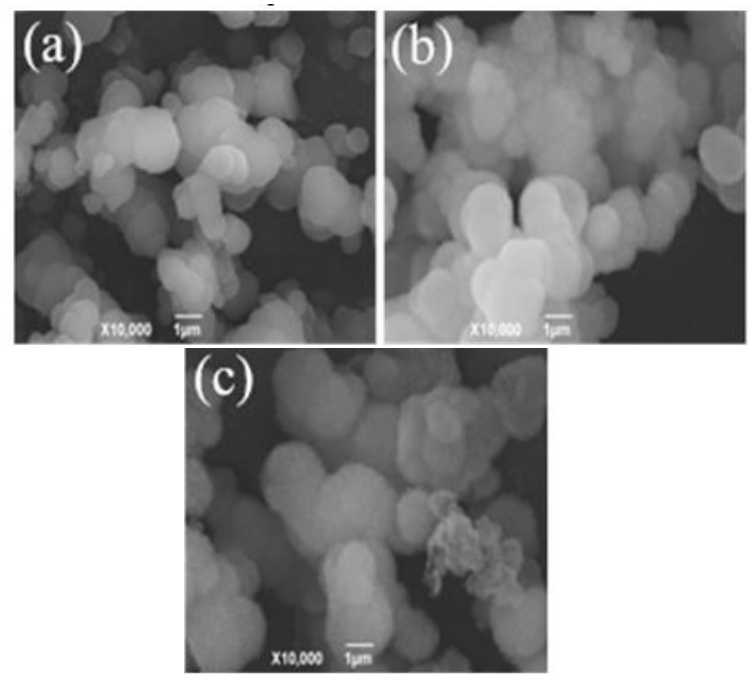

Figure 3. SEM images of Mg-Al LDH samples obtained at different hydrothermal temperature with the addition of $9 \mathrm{~mL}$ CDs solution (a: $90^{\circ} \mathrm{C}$; b: $120^{\circ} \mathrm{C}$; c: $150^{\circ} \mathrm{C}$ )

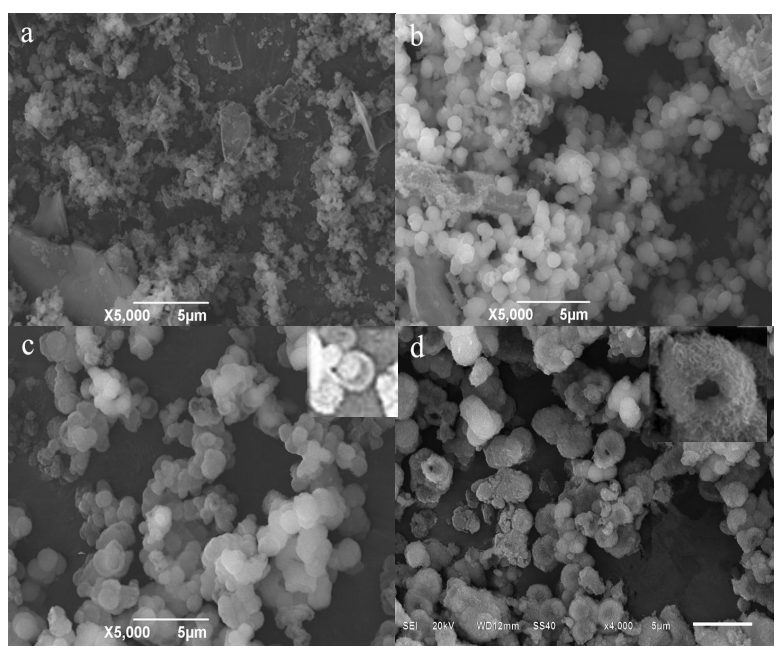

Figure 4. SEM images of Mg-Al LDH samples obtained at different reaction interval with the addition of $9 \mathrm{~mL} \mathrm{CDs}$ solution (a: $30 \mathrm{~min} ; \mathrm{b}: 1 \mathrm{~h}$; c: $3 \mathrm{~h}$; d: $5 \mathrm{~h}$ )

In order to elucidate the growth mechanism of hollow $\mathrm{Mg}-\mathrm{Al} \mathrm{LDH}$ microspheres, the samples at different growth period during the synthesis process of HHMs are investigated. The evolution of the sample morphology at different reaction interval is shown in Figure 4. At the initial stage $(0.5 \mathrm{~h})$, plenty of nanoparticles and some flaky blocks are observed (Figure 4a). With the prolongation of reaction time (2h), some flaky blocks almost disappeared and many particles with even diameter in hundreds of micron 
emerged in the samples (Figure 4b). The sample obtained at reaction time of $4 \mathrm{~h}$ is many particles with the diameter about $\sim 1$ um. Notably, quite a few particles are core-shell structure and small particles as core are encircled by thin shell (Figure 4c). When the reaction time reaches $10 \mathrm{~h}$, hollow microspheres are finally formed and the surface of microspheres is built by $2 \mathrm{~d}$ nanosheets (Figure $4 \mathrm{~d}$ ).

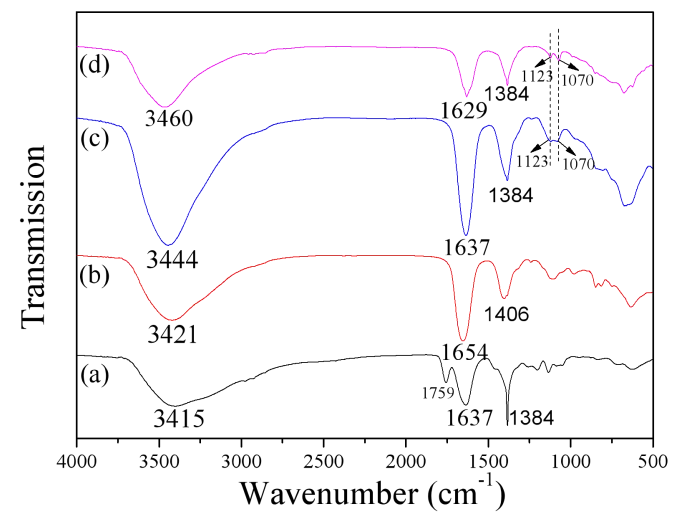

Figure 5. FTIR spectra of Mg-Al LDH samples obtained at different reaction interval with the addition of $9 \mathrm{~mL} \mathrm{CDs}$ solution (a: $30 \mathrm{~min}$; b: $1 \mathrm{~h}$; c: $3 \mathrm{~h}$; d: $5 \mathrm{~h}$ )

Figure 5 presents the FT-IR spectra of HHMs samples obtained at $0.5 \mathrm{~h}, 1 \mathrm{~h}, 2 \mathrm{~h}$ and $5 \mathrm{~h}$. Samples at $1 \mathrm{~h}$, $2 \mathrm{~h}$ and $5 \mathrm{~h}$ have similar patterns as shown in Figure $5 \mathrm{~b}-$ c. The broad transmission band at about $3450 \mathrm{~cm}^{-1}$ (Figure 5) corresponds to the H-bonding stretching vibrations of $\mathrm{OH}$ group in the hydroxide layer. The transmission band at $1636 \mathrm{~cm}^{-1}$ is ascribed to the vibration of $\mathrm{C}=\mathrm{O}$ and $\mathrm{COC}$ groups (oxygen-rich functional groups) of CDs. The transmission band at about $1000 \mathrm{~cm}^{-1}$ is ascribed to the vibrations of hydroxyl groups. Two bands in the low-frequency region around 725 and $530 \mathrm{~cm}^{-1}$ are attributable to M$\mathrm{O}$ stretching vibriations. Notably, a middle peak at $1800 \mathrm{~cm}^{-1}$ that belongs to is observed in the sample obtained at $0.5 \mathrm{~h}$ while disappeared at the samples of $1 \mathrm{~h}, 2 \mathrm{~h}$ and $5 \mathrm{~h}$. Furthermore, the intensity of transmission band attributed to the vibration of $\mathrm{C}=\mathrm{O}$ and C-O-C groups of CDs become weaker than that of samples obtained at $2 \mathrm{~h}$ and $5 \mathrm{~h}$. These indicate that a continuous growth and evaluation process happens with the increasing reaction time.

XRD patterns of the samples at different interval are shown in Figure 6. No obvious diffraction peak can be observed from Figure $6 \mathrm{a}$, indicating the phase at initial period is mainly amorphous. During the subsequent reaction process, crystal phase began to occur in the sample, and some diffraction peaks can be detected as shown in Figure $6 \mathrm{~b}$. The diffraction peaks of (003) and (006) correspond to an ordered stacking of the layers for LDH material. In Figure $6 \mathrm{c}$, the sample obtained at $5 \mathrm{~h}$ show more diffraction, indicating the increasing crystallization degree of the sample with the increasing reaction time. XRD pattern of the sample obtained at $10 \mathrm{~h}$ is shown in Figure $6 \mathrm{~d}$, typical diffraction peaks indexed by (003), (006), (009) and (110) in the XRD patterns suggest well-crystallized lamellate layers [7].

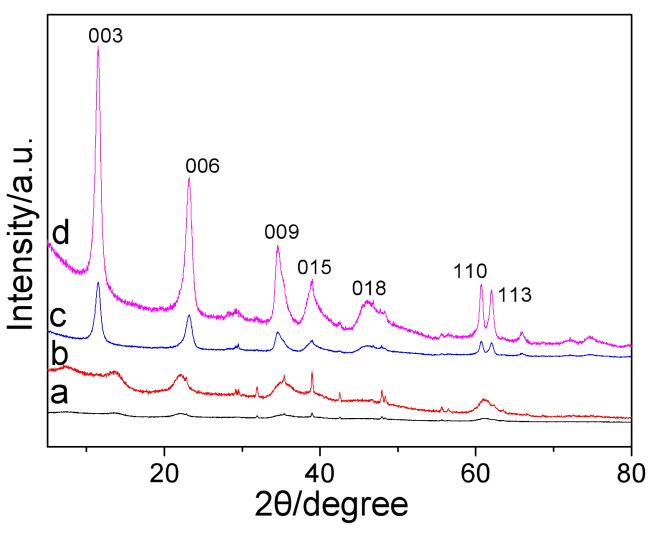

Figure 6. XRD patterns of $\mathrm{Mg}-\mathrm{Al} \mathrm{LDH}$ samples obtained at different reaction interval with the addition of $9 \mathrm{~mL} C D s$ solution (a: $30 \mathrm{~min} ; \mathrm{b}: 1 \mathrm{~h}$; $: 3 \mathrm{~h}$; $: 5 \mathrm{~h}$ )

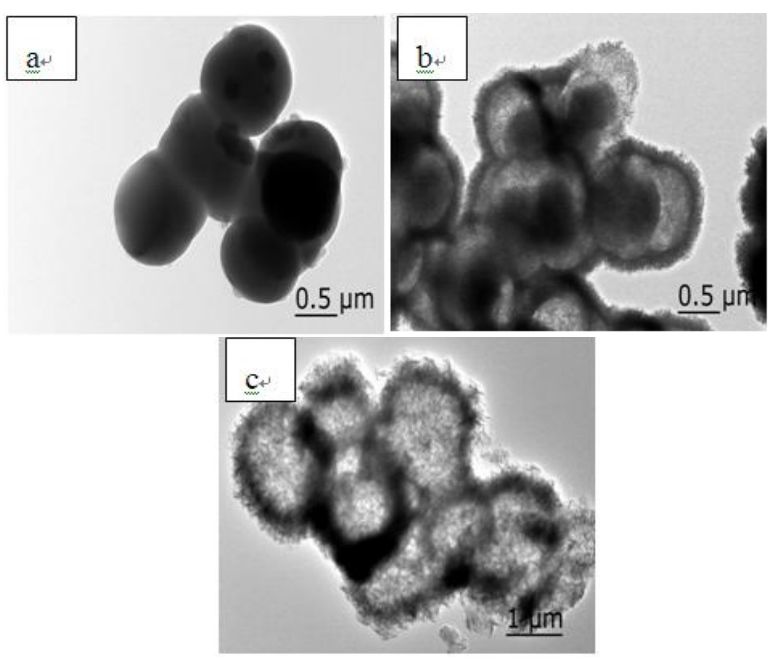

Figure 7. TEM images of the samples obtained at different growth period stages: (a) $1 \mathrm{~h}$; (b) $3 \mathrm{~h}$; (c) $5 \mathrm{~h}$.

The above-mentioned growth of HHMs is further testified by TEM analysis. Figure 7 shows TEM images of HHMs at the different periods at $1 \mathrm{~h}, 3 \mathrm{~h}$ and 5h. As shown in Figure $7 \mathrm{a}$, only solid microspheres obtained after a reaction time of $1 \mathrm{~h}$ are obtained and no hollow structures are observed. TEM images of the sample obtained after hydrothermal time of $3 \mathrm{~h}$ (Figure $7 b$ ) indicate the samples are core-shell structure and the solid microspheres become smaller compared with the samples obtained at $1 \mathrm{~h}$. As shown in TEM image of the samples prepared at 5h (Figure 7c), hollow interior appears in the center of the microsphere with the disappearance of core. At the same time, nanosheetlike structure at the shell of the hollow microspheres can also be observed.

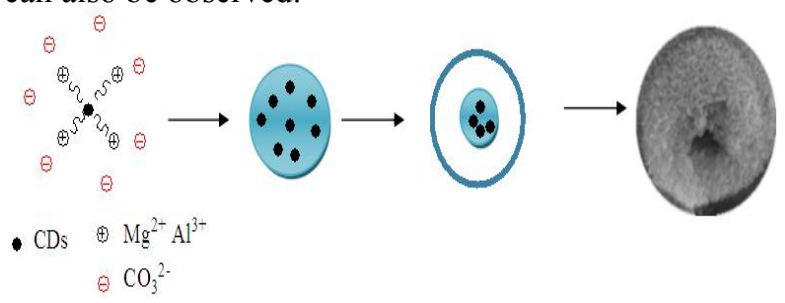

Scheme 1. Schematic diagram of the growth evolution for HHMs 
Based on the analyses of the FT-IR spectra and the $\mathrm{X}$-ray diffraction patterns, a possible formation mechanism for hierarchical hollow Mg-Al layered double hydroxide microspheres (HHMs) is illustrated in Scheme 1. At the initial stage, electron-rich oxygencontaining group of CDs attracts metal cations $\left(\mathrm{Mg}^{2+}\right.$, $\mathrm{Al}^{3+}$ ) to form complexing relationship. With the increasing reaction temperature and the release of $\mathrm{CO}_{3}{ }^{2-}$ from urea, nanoparticles and board-like product began to form. Subsequently, nanoparticles have evolved into submicrometer spheres with smooth surface and board-like product disappeared. However, the phase of these submicrometer spheres is unstable in experimental temperature, and the ostwald ripening process happened. The outside of submicrometer-sized spheres is firstly dissolved and the shell out of spheres formed because the crystallization is taking place at the same time. Firstly, LDH crystals with the high lateral growth rate grow along a direction, and form the curved LDH nanoplates. Subsequently, the unit of LDH nanoplates aggregate together and self-assemble into $3 \mathrm{D}$ ordered spherical structures. Judging from the SEM images of HHMs, LDH nanoplates on the surface of the generated microspheres are constructed in perpendicularly oriented and interlaced growth modes to minimize the surface energy of HHMs particles. On the basis of above analysis, the formation mechanism of HHMs is believed to be the result of the Ostwald ripening mechanism and the growth process is companied by the release and reconstruction between $\mathrm{LDH}$ and CDs, as revealed by FTIR analysis.

\subsection{Adsorption property of HHMs}
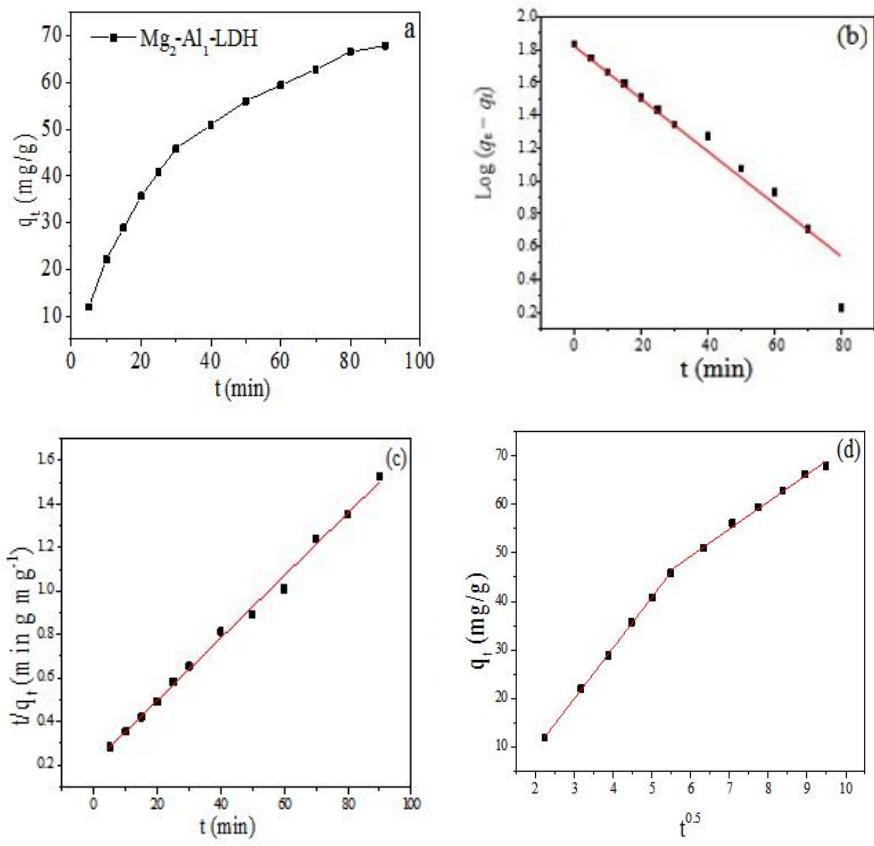

Figure 8. Effect of time profiles of CR adsorption onto HHMs (a) and fitting plots for adsorption kinetics of Pseudofirst-order model (b), Pseusecond-order model (c) and Intraparticle diffusion process $(\mathrm{d})$.
Table 1. Adsorption kinetics models and the related fitting parameters of CR adsorption onto HHMs

\begin{tabular}{lll}
\hline $\begin{array}{l}\text { Adsorption } \\
\text { kinetic model }\end{array}$ & Parameters & $\begin{array}{l}\mathrm{Mg}_{2}-\mathrm{Al}_{1}- \\
\mathrm{LDH}\end{array}$ \\
\hline \multirow{3}{*}{$\begin{array}{l}\text { Pseudo-first- } \\
\text { order }\end{array}$} & $q_{\mathrm{e}, \mathrm{exp}}\left(\mathrm{mg} \mathrm{g}^{-1}\right)$ & 67.92 \\
& $q_{\mathrm{e}, \mathrm{cal}}\left(\mathrm{mg} \mathrm{g}^{-1}\right)$ & 60.56 \\
& $K_{l}\left(\mathrm{~min}^{-1}\right)$ & 0.037 \\
& $R^{2}$ & 0.9538 \\
Pseudo-second- & $q_{\mathrm{e}, \mathrm{exp}}\left(\mathrm{mg} \mathrm{g}^{-1}\right)$ & 67.92 \\
order & $q_{\mathrm{e}, \mathrm{cal}}\left(\mathrm{mg} \mathrm{g}^{-1}\right)$ & 69.68 \\
& $K_{2}\left(\times 10^{-4} \mathrm{~g} \mathrm{mg}^{-1} \mathrm{~min}^{-1}\right)$ & 9.8 \\
& $R^{2}$ & 0.9955 \\
& $C_{l}\left(\mathrm{mg} \mathrm{g}^{-1}\right)$ & 11.26 \\
Intra-particle & $K_{i l}\left(\mathrm{mg} \mathrm{g}^{-1} \mathrm{~min}^{-1 / 2}\right)$ & 10.43 \\
diffusion & $R_{l}^{2}$ & 0.9994 \\
& $C_{2}\left(\mathrm{mg} \mathrm{g}^{-1}\right)$ & 15.67 \\
& $K_{i 2}\left(\mathrm{mg} \mathrm{g}^{-1} \mathrm{~min}^{-1 / 2}\right)$ & 5.60 \\
& $R_{2}^{2}$ & 0.9936 \\
\hline
\end{tabular}

${ }^{*}$ The $q_{\mathrm{e}}$ and $q_{\mathrm{t}}\left(\mathrm{mg} \mathrm{g}^{-1}\right)$ are the amounts of the CR adsorbed at equilibrium and at time $(\mathrm{min})$, respectively; $\mathrm{R}^{2}$ is the correlation coefficients. $K_{1}\left(\mathrm{~min}^{-1}\right), K_{2}\left(\mathrm{~g} \mathrm{mg}^{-1} \mathrm{~min}^{-1}\right)$ and $K_{i}$ $\left(\mathrm{mg} \mathrm{g}^{-1} \mathrm{~min}^{-1 / 2}\right)$ are the rate constant of pseudo-first-order adsorption, the pseudo-second-order rate constant at the equilibrium and the intra-particle diffusion rate constant, respectively.

It is well known that MgAl-LDH with positive charge can remove the pollutant with negative charge by electrostatic interaction. Figure $8 \mathrm{a}$ shows the influence of adsorption time on the uptake of CR onto HHMs. As can be seen, the uptake of CR gradually increases with increasing adsorption time. Adsorption capacity rapidly increased in the initial $30 \mathrm{~min}$ and the rate of increase slowly decreased until it nearly reached adsorption equilibrium. The pseudo -first, -secondorder and intra-particle diffusion kinetic models are used to investigate adsorption kinetics. The kinetic equation and corresponding estimated parameters with correlation coefficient are shown in Table 1. The parameters in first- and second- order models can be determined experimentally from plotting $\log \left(q_{\mathrm{e}}-q_{t}\right)$ vs. $t$, $\left(t / q_{t}\right)$ vs. $t$ and $q_{t}$ vs. $t^{0.5}$, respectively. The fitted linear regression plots are shown in Figure 8b-d. The obtained parameters are listed in Table 1 . The values of $R^{2}$ for pseudo-second-order are 0.99 , which was higher than those of other kinetic model. Furthermore, the calculated values of equilibrium adsorption capacities of CR by pseudo-second-order model are closer to the experimental results. The pseudo-second-order model is more suitable to describe adsorption behavior than other kinetic models and adsorption is ion exchange process [8]. At the same time, the intra-particle diffusion plot does not pass through the origin, indicating that the sorption process is controlled by more than one mechanism [9].

Adsorption performance with the variation of initial concentration under different adsorption temperature is showed in Figure 9. Adsorption capacity of $\mathrm{CR}$ at constant temperature is enhanced with increasing the initial CR concentration (Figure 9a). There is a rapid increase of adsorption capacity in lower initial CR concentration, and the increasing rate gradually decreases with the enhanced initial concentration. In addition, $\mathrm{q}_{\mathrm{e}}$ is gradually increasing with the increase of 
temperature, indicating adsorption of $\mathrm{CR}$ onto is endothermic process. The experimental data can be simulated by the Langmuir, Freundlich and Temkin isotherm models. The experimental data for adsorption are fitted to Linear Langmuir, Linear Freundlich and Temkin isotherm models as illustrated in Figure $9 \mathrm{~b}-\mathrm{d}$. The estimated model parameters and the correlation coefficient $\left(R^{2}\right)$ for the three models are shown in Table 2. The experimental data of CR adsorption can be well fitted by Langmuir and Temkin model, indicating that monolayer adsorption process occurs on the surface of LDH and binding energy uniformly distributed. In 298 $\mathrm{K}$, Temkin model is better fitting isotherm because of its higher $r^{2}$ value.
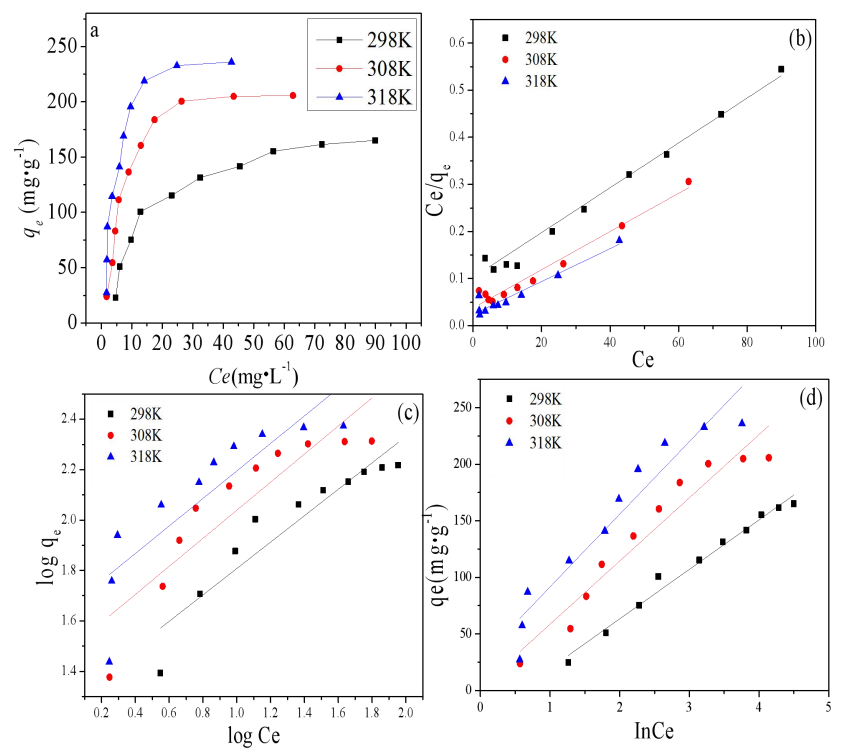

Figure 9. Effect of initial concentration of CR adsorption onto HHMs (a) and fitting plots for adsorption isotherm of Freundlich (b), Langmuir (c) and Temkin model.

Table 2. Adsorption isotherm models and the related fitting parameters of CR adsorption onto HHMs

\begin{tabular}{lllll}
\hline \multirow{2}{*}{$\begin{array}{l}\text { Isotherm } \\
\text { models }\end{array}$} & \multirow{2}{*}{$\begin{array}{l}\text { Isotherm } \\
\text { parameters }\end{array}$} & \multicolumn{3}{l}{ Temperature (K) } \\
\cline { 3 - 5 } & & \multicolumn{2}{l}{$\mathrm{Mg}_{2}-\mathrm{Al}_{1}$-LDH HHMs } \\
\cline { 3 - 5 } & & 298 & 308 & 318 \\
\hline \multirow{3}{*}{ Langmuir } & $\mathrm{q}_{\max }\left(\mathrm{mg} \mathrm{g}^{-1}\right)$ & 209.6 & 246.3 & 286.5 \\
& $K_{\mathrm{L}}\left(\mathrm{L} \mathrm{mg}^{-1}\right)$ & 0.047 & 0.108 & 0.145 \\
& $R^{2}$ & 0.948 & 0.966 & 0.915 \\
\hline \multirow{2}{*}{ Freundlic } & $K_{f}\left(\mathrm{mg}^{1-1 / 1} \mathrm{~L}^{1 / \mathrm{n}^{-1}}\right)$ & 19.26 & 30.37 & 44.62 \\
$\mathrm{~h}$ & $\mathrm{n}$ & 1.91 & 1.80 & 1.83 \\
& $R^{2}$ & 0.871 & 0.789 & 0.747 \\
\hline \multirow{2}{*}{ Temkin } & $\mathrm{A}$ & 0.57 & 1.05 & 1.53 \\
& $\mathrm{~B}$ & 43.78 & 55.88 & 64.29 \\
& $R^{2}$ & 0.983 & 0.958 & 0.912 \\
\hline
\end{tabular}

${ }^{*} \mathrm{q}_{\max }$ is the maximum amount of CR per unit weight of the absorbent at equilibrium $\mathrm{CR}$ concentration $C_{\mathrm{e}}$, and $K_{\mathrm{L}}$ is Langmuir constant related to the affinity of binding sites ( $\mathrm{L}$ $\mathrm{mg}^{-1}$ ) for Langmuir equation. $k_{\mathrm{F}}$ and $1 / n$ in Freundlich equation are constants that depict the adsorption capacity and the adsorption intensity, respectively. $A$ and $B$ in Temkin equation are the constant that reveal adsorption on the surface with per unit bounding energy.

$\varepsilon=\operatorname{RTLn}\left(1+1 / \mathrm{C}_{\mathrm{e}}\right)$
Table 3. Thermodynamics Parameters for Adsorption of CR noto HHMs

\begin{tabular}{llll}
\hline $\begin{array}{l}\text { Temperature } \\
(\mathrm{K})\end{array}$ & $\begin{array}{l}\Delta G^{\mathrm{o}} \\
\left(\mathrm{KJ} \mathrm{mol}^{-1}\right)\end{array}$ & $\begin{array}{l}\Delta H^{\mathrm{o}} \\
\left(\mathrm{KJ} \mathrm{mol}^{-1}\right)\end{array}$ & $\begin{array}{l}\Delta S^{\mathrm{o}} \\
\left(\mathrm{J} \mathrm{mol}^{-1} \mathrm{~K}^{-1}\right)\end{array}$ \\
\hline 298 & -8.65 & & \\
308 & -11.06 & 44.59 & 179.33 \\
318 & -12.19 & & \\
\hline
\end{tabular}

${ }^{*} \Delta G^{\circ}$ is standard free energy change; $\Delta H^{\circ}$ is standard enthalpy change $\left(\Delta H^{\circ}\right) ; \Delta S^{\circ}$ is standard entropy change. $\Delta \mathrm{H}^{\circ}$ and $\Delta \mathrm{S}^{\circ}$ were obtained from the slope and intercept of $\ln \mathrm{K}_{\mathrm{L}}$ against $1 / \mathrm{T}$

The thermodynamics parameters of adsorption under the different temperature conditions are calculated and listed in Table 3. The values of $\Delta G^{\circ}$ for the experimental temperatures are negative, indicating that adsorption of $\mathrm{CR}$ onto HHMs is spontaneous. Lower value of $\Delta G^{\circ}$ implies the stronger adsorption tendency. While, the value of $\Delta G^{\circ}$ gradually decreases with the increasing adsorption temperature, meaning that adsorption is a temperature-dependent process and higher temperature is favorable for adsorption. Furthermore, the positive value $\left(44.59 \mathrm{~kJ} \mathrm{~mol}^{-1}\right)$ of $\Delta H^{\circ}$ determinately proves adsorption phenomenon was endothermic. The positive value of $\Delta S^{\circ}$ indicates the increased randomness for adsorption.

\section{Conclusion}

In summary, CDs-controlled hierarchical $\mathrm{Mg}-\mathrm{Al}$ layered double hydroxide hollow microsphere has been successfully synthesized by hydrothermal method. CDs play an important role for the formation of hierarchical Mg-Al layered double hydroxide hollow microsphere. Ostwald ripening mechanism is suggested for the hierarchical formation of HHMs. The as-prepared HHMs can effectively remove the CR form wastewater. The kinetics of CR adsorption onto HHMs is examined using different kinetic models. The pseudo-secondorder equation is proved to be the ideal correlation of the sorption data. Langmuir and Temkin model are more suitable to plot the equilibrium data. Adsorption process is endothermic and spontaneous according to the thermodynamic parameters. These results indicated that the as-prepared HHMs possessed high potential as adsorbent in the application of anion dye wastewater treatment.

\section{References}

[1] Petcu A R, M Aurelia, Rogozea E A, et al. ACS Sustainable Chem. Eng. 5, 5273-5283, (2017).

[2] Song C 1, Zhao J H, Li H Y, et al. ACS Sustainable Chem. Eng. 6, 6876-6888, (2018).

[3] Ai L H, Yue H T, Jiang J, Nanoscale, 6, 1325313253, (2014).

[4] Maiti D, Mukhopadhyay S, Devi P S, ACS Sustainable Chem. Eng. 5, 11255-11267, (2017).

[5] Zhang D Q, Jia Z G, Luo G C, Chinese J. Inorg. Chem, 3, 2532-2545, (2018). 
[6] Xu J, Deng H H, Song J X, et al. J. Colloid Interf. Sci. 505 816-823, (2017).

[7] Wang R, Lu K Q, Tang Z R,et al. J. Mater. Chem. $A$, 5, 3717-3734, (2017).

[8] Meng F Q, Ma W, Wu L, et al. J. Taiwan. Inst. Chem E, 83, 192-203, (2018).

[9] Dong C L, Yuan X T, Wang X, et al. J. Mater. Chem. A, 4, 11292-11298, (2016). 